\title{
PREVALENCE OF CEPHALOSPORIN-RESISTANT GRAM-NEGATIVE BACILLI FROM CLINICAL SAMPLES
}

\author{
KAVIYARASAN G' ${ }^{1}$, RAJAMANIKANDAN KCP ${ }^{2}$, ARVIND PRASANTH D ${ }^{1 *}$ \\ ${ }^{1}$ Department of Microbiology, Periyar University, Salem, Tamil Nadu, India. ${ }^{2}$ Department of Microbiology, Jairam College of Arts and \\ Science, Salem, Tamil Nadu, India. Email: prasanthviji@gmail.com
}

Received: 13 June 2016, Revised and Accepted: 23 June 2016

\section{ABSTRACT}

Objective: Beta-lactams are the group of antibiotics that contain a ring called as "beta-lactam ring," which is responsible for the antibacterial activity. The presence of resistance among Gram-negative organisms is due to the production of beta-lactamases enzymes that hydrolysis the beta-lactam ring thereby conferring resistance to the organism. This study is undertaken to determine the prevalence of extended-spectrum beta-lactamase (ESBL) producing Gram-negative organism from clinical samples.

Methods: A total of 112 clinical samples were taken for this study. The combined disc synergistic test (CDST) was used for the phenotypic detection of ESBL producers from the clinical samples. The genotypic identification of ESBL producers was carried out by alkaline lysis method by isolation of plasmid DNA.

Result: A total of 87 bacterial isolates were isolated and identified. Among them, Klebsiella (41\%) was the predominant organism followed by Escherichia coli (33\%), Proteus (10\%), Pseudomonas (10\%), and Serratia (6\%). Among the various bacterial isolates, Klebsiella showed a higher percentage of resistance. The CDST showed that 8 isolates of Klebsiella, 3 isolates of E. coli, and 1 isolate of Pseudomonas were found to be ESBL producers. The genotypic confirmation showed that the two bacterial isolates, namely, Klebsiella and E. coli were found to possess temoniera (TEM) gene which was the 400-500 bp conferring resistance to the antibiotics.

Conclusion: The results of this study suggest that early detection of ESBL producing Gram-negative organism is a very important step in planning the therapy of patient in Hospitals. CDST continues to be a good indicator in the detection of ESBL producers.

Keywords: Beta-lactamases, Gram-negative bacilli, Extended-spectrum beta-lactamase, Resistance, Combined disc synergistic test.

(C) 2016 The Authors. Published by Innovare Academic Sciences Pvt Ltd. This is an open access article under the CC BY license (http://creativecommons. org/licenses/by/4. 0/) DOI: http://dx.doi.org/10.22159/ajpcr.2016.v9s2.13456

\section{INTRODUCTION}

Antibiotic resistance poses an important medical problem to public health as it poses a great challenge to microbiologist and pharmacologist in the treatment of infectious diseases caused by resistant organisms Beta-lactam antibiotics are mostly used for the treatment of these infections in the hospitals and health-care centers due to its broad spectrum of activity [1,2]. Frequent and improper usage of beta-lactam antibiotics leads to the development of resistance in the Gram-negative organism [3]. These resistant bacteria produce beta-lactamases enzymes which hydrolyze the amide bond of the beta-lactam ring. Beta-lactamases have been categorized into four groups based on their functions, namely, (a) Penicillinase, (b) extended-spectrum of betalactamases (ESBLs), and (c) AmpC and carbapenems [4].

Extended-spectrum beta-lactamase (ESBL) is a plasmid-mediated beta-lactamase which can resist and hydrolyze the first generation penicillins, second- and third-generation cephalosporins, and aztreonam. Nowadays, these enzymes hydrolyze even the fourthgeneration cephalosporins [5]. However, clavulanic acid (CAC) inhibits the activity of ESBLs because they are the beta-lactamase inhibitors [6] ESBL is generally produced by Klebsiella spp., Escherichia coli, and other Gram-negative bacilli. ESBL-Eb (Enterobacteriaceae) is not only reported to be isolated from hospitals but they are also present in our environments in the farm animals and derived foods, domestic and even in wild animals, healthy humans, wastewater, vegetables, etc. [7].

Unsuitable treatment of infections caused by ESBL producers has been increased mortality and hospital stay. Obligatory, we should confirmation of bacterial resistance pattern before starting treatment in health care and hospitals [8]. As these ESBLs producers are showing resistance to major antibiotics which are used for the treatment of pathogens, microbiologist uses higher antibiotics such as colistin and polymyxin B to treat these ESBLs producers. These drugs are not routinely used as they cause various side effects such as kidney and nerve damage. Most ESBLs are derivatives of the more common betalactamases known as temoniera (TEM) or sulfhydryl variable (SHV) types [9]. CTX M1, 2, 8, 9, and 25 then OXA are the genes responsible for the production of ESBLs [10]. Hence, identification of these ESBLs producers has become a very important problem in a clinical setting to avoid the prolonged stay of the patients in the hospitals and restrict the appropriate usage of antibiotics in the treatment. Hence, this present study was undertaken to find the prevalence of ESBLs producing Gramnegative organism from various clinical specimen collected from the local hospital and determine the genes conferring resistance to these organisms.

\section{METHODS}

\section{Sample collection}

A total of 112 clinical samples were collected from the local Medical Hospitals, Salem, Tamil Nadu, in sterile containers and transported immediately to the laboratory for future work.

\section{Isolation and identification}

All the samples were inoculated onto Mac Conkey's agar for the isolation of Gram-negative bacilli. The isolated organisms were identified and confirmed by Bergey's manual of determinative bacteriology.

\section{Antibiotic susceptibility test}

The antibiotics susceptibility testing of Gram-negative organisms was done following the CLSI guidelines using ceftazidime (CAZ), ceftriaxone, cefotaxime, amikacin, ampicillin, ciprofloxacin, co-trimoxazole, gentamicin, and imipenem. 
Phenotypic detection of ESBL producers

The Gram-negative isolates showing resistance to CAZ were screened for ESBL producers by combined disc synergistic test (CDST). CAZ-30 $\mu \mathrm{g}$ and $\mathrm{CAZ}+\mathrm{CAC}-30 / 10 \mu \mathrm{g}$ ) were used for this test. $0.5 \mathrm{McF}$ arland of the test culture was swabbed onto Mueller-Hinton agar plates. CAZ-30 $\mu \mathrm{g}$ and CAZ + CAC (CAC-30/10 $\mu \mathrm{g}$ ) were placed at a distance of $20 \mathrm{~mm}$ (center to center) on Mueller-Hinton agar plates. The plates were incubated for $24 \mathrm{hrs}$ at $37^{\circ} \mathrm{C}$. After the incubation period expanded zone of inhibition up to $5 \mathrm{~mm}$ around $\mathrm{CAZ}+\mathrm{CAC}$ disc than CAZ disc were confirmed as ESBL producers based on the CLSI guidelines.

\section{Genotypic detection of ESBL producers}

The genotypic identification of ESBL producers was carried out by alkaline lysis method by isolation of plasmid DNA following the method of Sadasivam and Manickam, 2008 with minor modifications. About $1 \mathrm{ml}$ of an overnight culture was transferred into an Eppendorf tube. The cells were sediment by centrifuging briefly $(5000 \mathrm{rpm})$ in the microfuge, and the supernatant was drained off. The pellet was resuspended by adding $100 \mu \mathrm{L}$ of solution $\mathrm{A}$, and the contents were mixed by vortex. Then, $100 \mu \mathrm{l}$ solution B was added and mixed well by invert the content (4-5 times). To the above viscous content, $100 \mu \mathrm{L}$ of solution $\mathrm{C}$ was added and the content was inverted 4-5 times to get mixed, the bulk of genomic DNA and other cell debris will precipitate into a viscous clump [23]. It was centrifuged at $12000 \mathrm{rpm}$ in micro centrifuge, and the clump was removed. The clear lysate (supernatant) was transferred to another Eppendorf tube. $150 \mu \mathrm{l}$ of $100 \%$ isopropanol was added and mixed well and centrifuged the content at 12000 rpm for 30 minutes. The supernatant was drained off, and $150 \mu \mathrm{L}$ of absolute alcohol was added and centrifuged the content at $10000 \mathrm{rpm}$ for 20 minutes. The supernatant was drained off and dissolved the DNA pellets with $20 \mu \mathrm{L}$ TE buffer. The extracted plasmid DNA was confirmed by running of agarose gel electrophoresis.

Isolates were screened for the resistance genes SHV, TEM, CTX-M, and OXA by a multiplex polymerase chain reaction (PCR) assay by following the protocol of Hong Fang et al., (2008) (Table 1). PCR amplification reactions were performed in a volume of $25 \mu \mathrm{l}$ containing $12.5 \mu \mathrm{l}$ of $\times 2$ Promega PCR Master Mix (USA), $0.2 \mu \mathrm{M}$ concentrations of each primer, and $2 \mu \mathrm{l}$ of DNA template. The cycling parameters were as follows: An initial denaturation at $95^{\circ} \mathrm{C}$ for 15 minutes followed by 30 cycles of $94^{\circ} \mathrm{C}$ for 30 seconds, $62^{\circ} \mathrm{C}$ for 90 seconds, and $72^{\circ} \mathrm{C}$ for 60 seconds and with

Table 1: Forward and reverse primer sequence of SHV, TEM, CTX $\mathrm{m}$, and OXA genes with amplification size

\begin{tabular}{lll}
\hline $\begin{array}{l}\text { Gene } \\
\text { name }\end{array}$ & Primer sequence & $\begin{array}{l}\text { Amplified } \\
\text { size (bp) }\end{array}$ \\
\hline SHV & CTT TAT CGG CCC TCA CTC AA & 237 \\
& AGG TGC TCA TCA TGG GAA AG & \\
TEM & $\begin{array}{l}\text { CGC CGC ATA CAC TAT TCT CAG AAT GA } \\
\text { ACG CTC ACC GGC TCC AGA TTT AT }\end{array}$ & 445 \\
CTXm & ATG TGC AGY ACC AGT AAR GTK ATG GC & 593 \\
& TGG GTR AAR TAR GTS ACC AGA AYC AGC GG & \\
OXA & ACA CAA TAC ATA TCA ACT TCG C & 813 \\
& AGT GTG TTT AGA ATG GTG ATC & \\
\hline
\end{tabular}

SHV: Sulfhydryl variable, TEM: Temoniera a final extension at $72^{\circ} \mathrm{C}$ for 10 minutes. The amplified PCR products were subjected to electrophoresis at a $1.5 \%$ agarose gel in $\times 1 \mathrm{TBE}$ buffer. A 100 bp ladder molecular weight marker (Helini, India) was used to measure the molecular weights of amplified products.

\section{RESULTS}

A total of 112 clinical samples which included 39 urine samples, 30 Swab, 27 Pus samples, and 16 Sputum were taken for this study. A total of 87 bacterial isolates were identified. Among them, Klebsiella (41\%) was the predominant organism followed by E. coli (33\%), Proteus (10\%), Pseudomonas (10\%), and Serratia (6\%).

Among the various bacterial isolates, Klebsiella showed a higher percentage of resistance compared to other bacterial isolates (Table 2). For the detection of ESBL producers using CDST 29 isolates were taken of which 8 isolates of Klebsiella, 3 isolates of E. coli, and 1 isolate of Pseudomonas were found to be ESBL producers (Fig. 1).

\section{Genotypic detection of ESBL producers}

The results of the multiplex PCR showed that the two bacterial isolates were found to possess TEM gene which was $400-500$ bp as confirmed by running the PCR amplified product on the agarose gel electrophoresis. This gene is said to be responsible for conferring resistance by the production of ESBL enzyme against the third generation of cephalosporin antibiotics (Fig. 2).

The extracted plasmid DNA of Klebsiella spp. was marked as Lane 1; the extracted plasmid DNA E. coli was marked as Lane 2.

\section{DISCUSSION}

In our study, 8 isolates of Klebsiella, 3 isolates of E. coli, and 1 isolate of Pseudomonas were found to be ESBL producers out of 87 isolates. The multiplex PCR showed that the presence of TEM gene which is responsible for the resistance. The results of this study were similar to the one observed by Mojtaba et al., in which presence of TEM and SHV genes were found in $65.8 \%$ and $15 \%$ of isolates, respectively. The presence of both TEM and SHV was seen in 14 isolates (19.2\%) [11].

In this study, Klebsiella, E. coli, and Pseudomonas were found to be ESBL producers which is similar to one reported by Chong et al. in various clinical samples. In their study, from 2003 to 2011, the main ESBL-

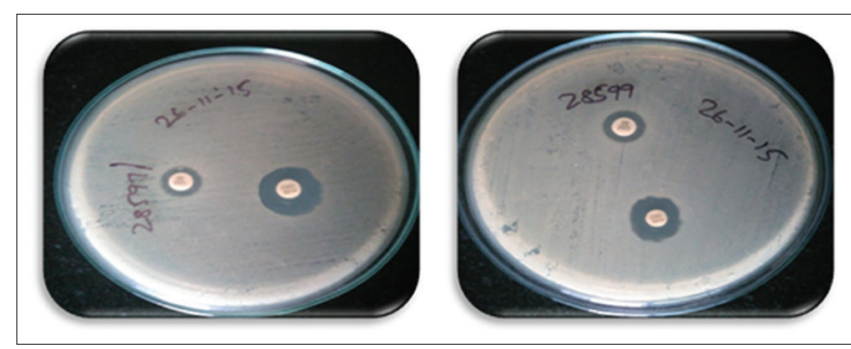

Fig. 1: Phenotypic detection of extended-spectrum beta-lactamase producers in this study. Figure is showing the enhancement zone of inhibition; left - Klebsiella; right - Escherichia coli

Table 2: Resistant pattern of the Gram-negative organisms isolated from clinical specimens in this study

\begin{tabular}{|c|c|c|c|c|c|c|c|c|}
\hline \multirow[t]{2}{*}{ Name of the organisms } & \multirow[t]{2}{*}{ Total Number of isolates } & \multicolumn{7}{|c|}{ Antibiotics (number of isolates and \% of resistance) } \\
\hline & & PIP & CIP & GEN & AK & ATM & CAZ & IPM \\
\hline Klebsiella & 28 & $8(12)$ & $16(24)$ & $8(12)$ & $1(1)$ & 20 (29) & $15(22)$ & $1(1)$ \\
\hline E. coli & 22 & $3(6)$ & $17(33)$ & $4(8)$ & - & $18(35)$ & $9(18)$ & - \\
\hline Proteus & 7 & $2(8)$ & $3(13)$ & $5(22)$ & 3 (13) & $5(22)$ & 3 (13) & $2(9)$ \\
\hline Pseudomonas & 7 & - & $2(14)$ & $3(22)$ & $3(22)$ & $3(21)$ & $2(14)$ & $1(7)$ \\
\hline Serratia & 4 & - & $1(25)$ & $2(50)$ & - & $1(1)$ & - & - \\
\hline
\end{tabular}

PIP: Piperacillin tazobactam, CIP: Ciprofloxacin, GEN: Gentamycin, AK: Amikacin, ATM: Azithromycin, CAZ: Ceftazidime, IMP: Imipenem, E. coli: Escherichia coli 


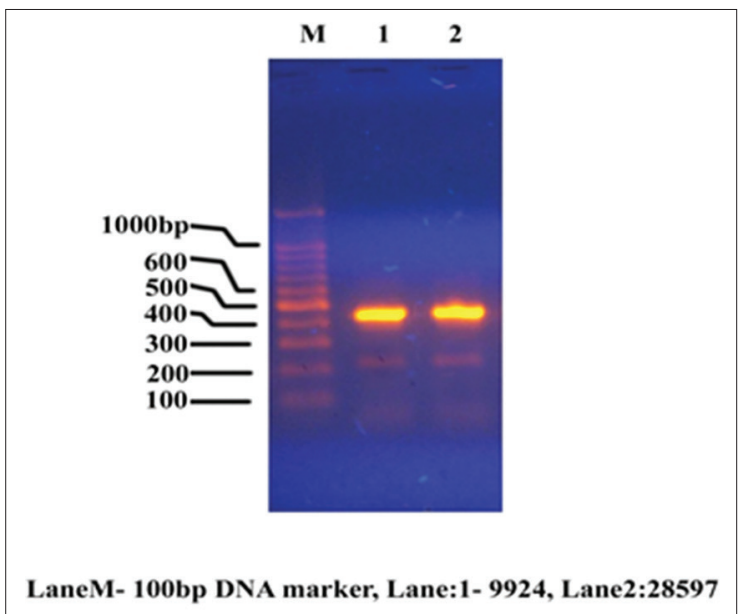

Fig. 2: Genotypic detection of extended-spectrum beta-lactamase producers in this study

producing bacteria isolated from outpatients were E. coli, Klebsiella pneumoniae, and Proteus mirabilis and 321 (6.3\%) of 5137 isolates were identified as ESBL producers. The number of each ESBL-producing bacterium detected was compared between out and inpatients in our hospital. ESBL producing E. coli were isolated in the year 2003. These strains steadily increased in number and reached $\sim 20 \%$ in 2011. During the same period, the out and inpatients also carried ESBLs in other bacteria, including $K$. pneumoniae and P. mirabilis. Interestingly, the frequent detection of ESBLs was first observed in the E. coli strains and was followed by the K. pneumoniae and P. mirabilis strains, irrespective of whether the patients were out-or inpatients. The detection rates of ESBL-producing K. pneumoniae and P. mirabilis strains increased during recent years, similar to that of the E. coli strains, and reached $\sim 10$ and $\sim 30 \%$, respectively $[12,13]$.

The current study has proved that most of the isolates were susceptible to imipenem and amikacin. In some previous study, many isolates were showed $100 \%$ sensitivity to imipenem and tigecycline. By the phenotypic confirmatory test, the prevalence of ESBL among $E$. coli isolates was found to be $36 \%$ [14]. The change in the antibiotic phenotype pattern in different ESBLs clearly differentiated the resistance mechanism of beta-lactamase producing isolates which was resolved by PCR, which accurately distinguished between different types of ESBL genes.

\section{CONCLUSION}

From the results of this study, it can be concluded that the early detection of ESBL producing Gram-negative organism is a very important step in not only reducing the mortality but also reducing the prolonged stay of patients in the Hospitals. CDST continues to be a good indicator in the detection of ESBL producers. However, a proper Coordination is very essential among clinicians, pharmacologists, and the microbiologist in the emergence and prevention of drug resistance strains.

\section{REFERENCES}

1. Bradford PA. Extended-spectrum beta-lactamases in the 21st century: Characterization, epidemiology, and detection of this important resistance threat. Clin Microbiol Rev 2001;14(4):933-51.

2. Qureshi WK, Palayekar V, Dayan E, Mack JP, Rojtman A. Combating the antibiotic resistance threat. Int J Pharm Pharm Sci 2015;7(2):68-72.

3. Samaha-Kfoury JN, Araj GF. Recent developments in beta-lactamases and extended spectrum beta-lactamases. BMJ 2003;327(7425):1209-13.
4. Philippon A, Arlet G, Jacoby GA. Plasmid-determined AmpC Type beta-lactamases. Antimicrob Agents Chemother 2002;46(1):1-11

5. Paterson DL, Bonomo RA. Extended-spectrum beta-lactamases: A clinical update. Clin Microbiol Rev 2005;18(4):657-86.

6. Mohanty S, Gaind R, Ranjan R, Deb M. Use of the cefepimeclavulanate ESBL Etest for detection of extended-spectrum betalactamases in AmpC co-producing bacteria. J Infect Dev Ctries 2009;4(1):24-9.

7. Ben Slama K, Ben Sallem R, Jouini A, Rachid S, Moussa L, Sáenz Y, et al. Diversity of genetic lineages among CTX-M-15 and CTX-M-14 producing Escherichia coli strains in a Tunisian hospital. Curr Microbiol 2011;62(6):1794-801.

8. Pratibha JS, Manita TW. Antibacterial activity of honey against ESBL producing Klebsiella pneumoniae from burn wound infections. Int J Curr Pharm Res 2015;7(2):32-6.

9. Mehrgan H, Rahbar M. Prevalence of extended-spectrum betalactamase-producing Escherichia coli in a tertiary care hospital in Tehran, Iran. Int J Antimicrob Agents 2008;31(2):147-51.

10. Pfeifer Y, Cullik A, Witte W. Resistance to cephalosporins and carbapenems in gram-negative bacterial pathogens. Int J Med Microbiol 2010;300(6):371-9.

11. Moosavian M, Deiham B. Distribution of TEM, SHV and CTX-M genes among ESBL-producing Enterobacteriaceae isolates in Iran. Afr J Microbiol Res 2012;6(26):5433-9.

12. Chong Y, Shimoda S, Yakushiji H, Ito Y, Miyamoto T, Kamimura T, et al. Community spread of extended-spectrum beta-lactamase-producing Escherichia coli, Klebsiella pneumoniae and Proteus mirabilis: A longterm study in Japan. J Med Microbiol 2013;62:1038-43.

13. Sandhiya R, Priya RL, Selvam E. Antibiotic susceptibility pattern and ESBL prevalence in Escherichia coli isolates from pus samples in a tertiary care hospital. Int J Pharm Pharm Sci 2015;7(3):263-4.

14. Riaz S, Bashir MF. Phenotypic and molecular characterization of plasmid-encoded extended spectrum beta-lactamases produced by Escherichia coli and Klebsiella spp from Lahore, Pakistan. Trop J Pharm Res 2015;14(9):1597-604.

15. Kao CC, Liu MF, Lin CF, Huang YC, Liu PY, Chang CW, et al. Antimicrobial susceptibility and multiplex PCR screening of AmpC genes from isolates of Enterobacter cloacae, Citrobacter freundii, and Serratia marcescens. J Microbiol Immunol Infect 2010;43(3):180-7.

16. Clinical Laboratory Standards Institute. Performance Standards for Antimicrobial Susceptibility Testing. $22^{\text {nd }}$ Informational Supplements: CLSI Document; M100-S22. Wayne, PA, USA: CLSI; 2012.

17. Chandel DS, Johnson JA, Chaudhry R, Sharma N, Shinkre N, Parida S, et al. Extended-spectrum beta-lactamase-producing gram-negative bacteria causing neonatal sepsis in India in rural and urban settings. J Med Microbiol 2011;60:500-7.

18. Sharma M, Pathak S, Srivastava P. Prevalence and antibiogram of extended spectrum beta-lactamase (ESBL) producing gram negative bacilli and further molecular characterization of ESBL producing Escherichia coli and Klebsiella spp. J Clin Diagn Res 2013;7(10):2173-7.

19. Behroozi A, Rahbar M, Yousefi JV. Frequency of extended spectrum beta-lactamase (ESBLs) producing Escherichia coli and Klebseilla pneumonia isolated from urine in an Iranian 1000-bed tertiary care hospital. Afr J Microbiol Res 2010;4(9):881-4.

20. Rawat D, Nair D. Extended-spectrum beta-lactamases in gram negative bacteria. J Glob Infect Dis 2010;2(3):263-74.

21. Mohamudha PR, Srinivas AN, Rahul D, Harish BN, Parija SC Molecular epidemiology of multidrug resistant extended-spectrum beta-lactamase producing Klebsiella pneumoniae outbreak in a neonatal intensive care unit. Int J Collab Res Intern Med Public Health 2010;2(7):226-38

22. Pitout JD, Laupland KB. Extended-spectrum beta-lactamase-producing Enterobacteriaceae: An emerging public-health concern. Lancet Infect Dis 2008;8(3):159-66.

23. Sadasivam S, Manickam A. Biochemical Methods. $3^{\text {rd }}$ ed. New Delhi, India: New Age International Publishers; 2008.

24. Zahar JR, Lortholary O, Martin C, Potel G, Plesiat P, Nordmann P Addressing the challenge of extended-spectrum beta-lactamases. Curr Opin Investig Drugs 2009;10(2):172-80s. 